\title{
Control of non-homeostatic feeding in sated mice using associative learning of contextual food cues
}

\author{
Sarah A. Stern ${ }^{1}$ - Katherine R. Doerig ${ }^{1}$ Estefania P. Azevedo ${ }^{1} \cdot$ Elina Stoffel $^{1}$ - Jeffrey M. Friedman ${ }^{1,2}$
}

Received: 26 October 2017 / Revised: 31 January 2018 / Accepted: 13 March 2018 / Published online: 6 June 2018

(c) The Author(s) 2018. This article is published with open access

\begin{abstract}
Feeding is a complex motivated behavior controlled by a distributed neural network that processes sensory information to generate adaptive behavioral responses. Accordingly, studies using appetitive Pavlovian conditioning confirm that environmental cues that are associated with food availability can induce feeding even in satiated subjects. However, in mice, appetitive conditioning generally requires intensive training and thus can impede molecular studies that often require large numbers of animals. To address this, we developed and validated a simple and rapid context-induced feeding (Ctx-IF) task in which cues associated with food availability can later lead to increased food consumption in sated mice. We show that the associated increase in food consumption is driven by both positive and negative reinforcement and that spaced training is more effective than massed training. Ctx-IF can be completed in $\sim 1$ week and provides an opportunity to study the molecular mechanisms and circuitry underlying non-homeostatic eating. We have used this paradigm to map brain regions that are activated during Ctx-IF with cFos immunohistochemistry and found that the insular cortex, and other regions, are activated following exposure to cues denoting the availability of food. Finally, we show that inhibition of the insular cortex using GABA agonists impairs performance of the task. Our findings provide a novel assay in mice for defining the functional neuroanatomy of appetitive conditioning and identify specific brain regions that are activated during the development of learned behaviors that impact food consumption.
\end{abstract}

\section{Introduction}

Associative learning is a fundamental process that enables organisms to make adaptive decisions based on prior outcomes. However, in some cases, associative learning may also lead to maladaptive decisions, as in the case of drug addiction and obesity [1]. Obesity is a growing problem in the developed world, as 30\% of adult Americans are currently classified as overweight or obese [2, 3]. Though decades of research have elucidated numerous genetic factors underlying obesity, monogenetic disorders do not

Electronic supplementary material The online version of this article (https://doi.org/10.1038/s41380-018-0072-y) contains supplementary material, which is available to authorized users.

Jeffrey M. Friedman

friedj@mail.rockefeller.edu

1 Laboratory of Molecular Genetics, Rockefeller University, New York, NY 10065, USA

2 Howard Hughes Medical Institute, Chevy Chase, MD, USA account for the majority of cases [4]. Furthermore, environmental factors can also play an important role in overeating and weight gain. Thus, external motivating factors, including easy access to high-energy food, as well as cognitive and emotional cues, can lead to overeating and even binge eating [5-8]. Consistent with this, it has been demonstrated in both humans and rodents that environmental cues that are paired with food delivery can augment subsequent feeding responses. For example, Weingarten used a Pavlovian conditioning paradigm to show that a cue paired with food delivery when rats were hungry could later be used to decrease the latency to eat even when rats were sated [9]. In contrast, an unpaired cue did not affect the latency to eat. More recently, it has been demonstrated in both rats [10] and mice [11] that visual and auditory cues can also be used to elicit overeating in sated animals after Pavlovian training.

Pavlovian conditioning is an extremely well-studied paradigm and has been used to study many behaviors, in particular feeding and fear [12, 13]. Indeed, Pavlov's original studies paired food and a sound in dogs [14], highlighting the powerful motivation of food as a 
reinforcer. Conditioning experiments can be further subcategorized as either cued or contextual conditioning depending on the type of sensory stimulus that is provided. For example, cued fear conditioning, which measures the freezing response after pairing discrete visual or auditory cues with footshocks, can be demonstrated in as little as one training session [15]. In contrast, conditioning animals to eat even when sated using an analogous cueinduced feeding task with visual or auditory cues requires more extensive training in chronically underfed animals, and it can take as long as 1 month to fully train an animal [11].

As an alternative, contextual training has also been used to link associative cues to a response. In previous studies of fear conditioning, a specific context (e.g., a behavioral chamber which provides a variety of different sensory cues) can serve as the conditioned stimulus. For example, it has been shown that placing animals in a novel context paired to a specific stimulus (e.g., footshocks) can induce the subsequent conditioned response (CR) of increased freezing in a single trial [15]. The contextual cues serve as a general predictive environment for a specific outcome rather than the onset of the single sensory input such as an auditory or visual cue as employed in cued Pavlovian conditioning [16].

While context-induced feeding (Ctx-IF) has been used to potentiate food intake in sated rats [17], this paradigm has not been evaluated in mice. In this report we tested whether context, rather than discrete cues, could be used to induce a conditioned response of overeating in mice. We tested this by placing fasted mice in a novel context where food was made available. We show that, similar to contextual fear conditioning, context can serve as a strong cue to induce overeating in sated mice and the use of this approach leads to similarly robust conditioning when compared to the use of an established cued conditioning protocol with a single defined stimulus. We then used this assay to establish optimal conditions for inducing the conditioned response by varying intertrial intervals. We also defined the emotional valence (positive or negative) driving the feeding response. In order to determine which brain regions might be involved in regulating conditioned overeating, we then used immediate early gene mapping to identify several brain regions that are activated in conditioned animals. Finally, we infused GABA agonists prior to Ctx-IF testing to show that the proper function of the insular cortex, one of the brain regions that is activated by the novel context, is necessary for the conditioned response. The high throughput and convenience of the context-induced feeding protocol will facilitate further experiments to define the specific neural populations and circuits that control the overconsumption response.

\section{Methods}

\section{Mice}

All experiments performed in these studies were approved by the Rockefeller University Institutional Animal Care and Use Committee and were in accordance with the National Institute of Health guidelines. Male wild-type C57BL6/J mice (The Jackson Laboratory, Bar Harbor, ME; RRID: IMSR_JAX:000664) were between 10-20 weeks at the start of behavioral testing. Mice were group housed on a $12 \mathrm{~h}$ light/dark cycle with ad libitum access to water and standard mouse chow, PicoLab Rodent Diet (Lab Diet, St. Louis, MO), except when single housing or fasting is noted below. Mice were handled for $1-2 \mathrm{~min}$ per day for 4 days prior to the start of behavioral procedures.

\section{Cued-IF}

Mice were trained similarly as described [11] with the following changes. Mice were food restricted to $\sim 85 \%$ ad libitum weight by providing $\sim 1 / 3$ standard food pellet per day for 1 week prior to the start of training. Weights were taken prior to food restriction and every day before food delivery to ensure adequate weight loss. Following the initial food restriction, mice were trained on a "simple" conditioning paradigm for 5 days and then a "discrimination" phase for 9 days.

Conditioning took place in Coulbourn Instruments (Whitehall, PA) rat-sized operant chambers outfitted with a house light, a blue LED and an automated food well. The house light and blue LED served as the "light" stimuli; the tones consisted of either white noise or a $2.5 \mathrm{kHz}$ tone. During the "simple" conditioning, mice were placed into the chamber and the CS + tone + light combination (balanced between groups) was played for 2 -sec every $30-90 \mathrm{sec}$ at random intervals, with a total of 30 cues presented over a $30 \mathrm{~min}$ conditioning session. Each presentation coterminated with delivery of a $20 \mathrm{mg}$ chocolate-flavored Precision Pellet (Bioserv, Flemington, NJ, Catalog \# F05301). Mice were observed to determine whether they nose-poked to the food well during each cue presentation and the \# of pellets consumed was counted at the end of the session. The "discrimination" sessions were conducted in the same manner, except that $15 \mathrm{CS}+$ (tone + light, paired with food) and $15 \mathrm{CS}-$ (alternative tone + light, not paired with food) presentations were randomly given every 30-90 sec over the course of a 30 min conditioning session. Following the last "discrimination" session mice were returned to ad libitum feeding for 5 days before testing. Testing consisted of mice being placed into the chambers for two $10 \mathrm{~min}$ sessions separated by a $5 \mathrm{~min}$ intertrial interval, in which the mouse was placed back into his home cage. In the 
first session mice were either presented with $10 \mathrm{CS}+$ presentations or $\mathrm{CS}-$ presentations. In the second session mice received 10 presentations of whichever CS they did not receive in the first session. The order of presentation was counterbalanced. In both cases, there were $2 \mathrm{~g}$ of Precision Pellets freely available in the food cup. Pellets were weighed after each session to determine consumption. During testing, the investigator was blind to the experimental conditions.

\section{Context-IF}

Prior to habituation mice were given 5-10 chocolate flavored $20 \mathrm{mg}$ Precision Pellets, as above, during each day of handling to prevent neophobia. Mice were habituated to two different contexts. Contexts were easily distinguishable based on shape, size, floor texture and were in different rooms (Supplementary Figure 1). Habituation consisted of $20 \mathrm{~min}$ exposure to each context. Mice were returned to their home cages after habituation, and cages were designated as either "Fasted" or "Fed Controls." One hour later, all cages were changed to prevent food dust on the floor from being consumed, and "Fed controls" continued to have ad libitum access to chow while "Fasted" mice did not receive food for the next $24 \mathrm{~h}$. The next day mice were trained to associate food delivery with one of the two contexts. Training consisted of $30 \mathrm{~min}$ exposure to the context with $2 \mathrm{~g}$ of Precision Pellets freely available in a food well. Pellets were counted after the training session to determine food consumption. Mice continued to be fasted or fed and were trained again the next day. One hour after the second training session, all mice were returned to ad libitum feeding for $48 \mathrm{~h}$ at which time, testing was conducted. Testing consisted of $20 \mathrm{~min}$ exposure to both contexts with $2 \mathrm{~g}$ of Precision Pellets freely available in a food well. Pellets were again counted after testing to determine food consumption. The order of context presentation during habituation, training and testing sessions were all counterbalanced to prevent ordering effects. During testing, the investigator was blind to the experimental conditions.

\section{Massed training}

The protocol was conducted as described above with the following changes. Training occurred in 2 sessions over the course of one day. Mice were trained for $30 \mathrm{~min}$ in the morning, and $5 \mathrm{~h}$ later, were trained again for $30 \mathrm{~min}$. One hour after the second training session, all mice were placed back on ad libitum food access until testing occurred $48 \mathrm{~h}$ later. To increase motivation to consume food during training, a separate group of animals went through the same protocol, but were fasted for $48 \mathrm{~h}$ before the one-day training protocol.

\section{Spaced training}

The protocol was conducted as described above with the following changes. After the first training session, all mice were placed back onto ad libitum food access for $24 \mathrm{~h}$. After those $24 \mathrm{~h}$, "fasted" mice again had their food removed for the next $24 \mathrm{~h}$ before the second training session (total of 48 $\mathrm{h}$ between training sessions). One hour after the second training session, all mice were placed back on ad libitum food access until testing occurred $48 \mathrm{~h}$ later.

\section{Negative valence}

The protocol was conducted as described above with the following changes. Mice were trained as described, but "fasted" mice were further subdivided into two groups. "Positive valence" mice were trained as described above with Precision Pellets freely available during training. "Negative valence" mice were fasted prior to training, but did not receive Precision Pellets in the training context. To control for food intake, they received a paired amount of standard chow in their home cage following training. In order to assess the metabolic status of the mice, mice were weighed during handling and throughout the behavioral protocol.

\section{Immediate early gene mapping}

Mice were trained in Ctx-IF using the original protocol described above, but were tested without food in order to assess activation in response to the context itself. A group of Naïve mice were handled but not trained or tested. Thirty minutes after being tested in $\mathrm{Ctx}+$ or $\mathrm{Ctx}-$, both groups of mice were perfused using $4 \%$ paraformaldehyde (PFA). Brains remained overnight in 4\% PFA before being transferred to phosphate-buffered saline (PBS) and processed for immunohistochemistry. Brains were sectioned at $50 \mu \mathrm{m}$ in 4 serial sections. Sections were washed $3 \times$ for $15 \mathrm{~min}$ in PBST (PBS-0.1\% TritonX) and blocked in 3\% goat serum in $3 \%$ BSA with $0.05 \%$ sodium azide. Sections were then incubated overnight with primary cfos antibody (Cell Signaling, Danvers, MA, dilution 1:500), washed $3 \times$ with PBST and then incubated for $1 \mathrm{~h}$ at RT with goat anti rabbit AlexaFluor 488 secondary antibody (Thermo Fisher Scientific, Waltham, MA, dilution 1:1000) and washed again $3 \times$ in PBST. Sections were mounted using Vectashield with DAPI (Vector Labs, Burlingame, CA) and imaged using an Inverted LSM 780 laser scanning confocal microscope (Zeiss, Thornwood, NY). To ensure valid comparisons, equivalent sections from the Naïve, Ctx - and $\mathrm{Ctx}+$ groups were imaged with the same settings (laser power, gain and digital offset) and any postacquisition manipulations were also made equivalently in both groups. Quantifications were made using ImageJ thresholding and particle analysis by an experimenter blind to conditions. 


\section{Stereotaxic surgery and cannula implants}

Mice were anesthetized with $3.5 \%$ isoflurane, placed in a stereotaxic frame (Kopft Instruments, Tujunga, CA), and maintained at $1.5 \%$ isoflurane. The craniotomy was performed using a dental drill (Dremel), and stainless steel guide cannulae (28-gauge, Plastics One, Roanoke, VA) were stereotactically implanted to bilaterally target the insular cortex $(0.26 \mathrm{~mm}$ anterior to the bregma; $3.9 \mathrm{~mm}$ lateral from midline; and $3.0 \mathrm{~mm}$ ventral from the skull surface) and fixed with dental cement. Mice were monitored for $72 \mathrm{~h}$ to ensure full recovery, were single housed, and 2-3 weeks later were used in experiments. Fifteen minutes before Ctx-IF testing, mice received bilateral injections of muscimol (Sigma, St. Louis, MO) and baclofen (Sigma) $(0.05 \mu \mathrm{g} / \mu \mathrm{L}$ and $0.02 \mu \mathrm{g} / \mu \mathrm{L}$, respectively). Injections were delivered in a volume of $0.3 \mu \mathrm{L}$ per side and used a 33gauge needle that extended $0.8 \mathrm{~mm}$ beyond the tip of the guide cannula (total ventral depth $=3.8 \mathrm{~mm}$ ). Guide cannulae were connected via polyethylene tubing to Hamilton syringes. All infusions were delivered at a rate of $0.1 \mu \mathrm{L} /$ min using an infusion pump (Harvard Apparatus, Holliston, MA). The injection needle was left in place for $1 \mathrm{~min}$ after the injection to allow complete dispersion of the solution.

To verify proper placement of cannula implants, at the end of the behavioral experiments, mice were perfused with $4 \%$ paraformaldehyde in PBS and brains were post-fixed in the same solution. No animals were excluded for improper cannula placement. Forty micrometer coronal sections were cut through the relevant brain region and examined under a light microscope.

\section{Statistical analyses}

Two-way analysis of variance (ANOVA) followed by the Sidak's multiple comparisons test, One-way ANOVA followed by Neuman Keul's multiple comparisons test or unpaired Student's $t$ test was used for statistical analyses. All graphs represent mean $+/$ - S.E. Statistics were calculated using Graphpad Prism 6. Group sizes were based on power calculations conducted prior to the experiments and no animals were excluded from analysis.

\section{Results}

\section{Context is sufficient to drive an overeating response in sated mice}

In this study we set out to identify and test the function of brain regions that play a role in associative learning to control increased feeding in sated animals. We first confirmed that discrete paired auditory and visual cues can drive overeating as previously described [11]. In these cueinduced feeding experiments (Fig. 1a), mice were food restricted until they weighed $\sim 85 \%$ of their baseline ad libitum weight for 1 week prior to training. Mice were then trained for 5 days to retrieve a food pellet whose delivery was paired to a 2 -sec presentation of a conditioned stimulus $(\mathrm{CS}+)$, which consisted of a combination of tone + light. Mice were then trained over 9 subsequent sessions to discriminate between the CS+ and an unpaired stimulus, (CS - ), balanced between groups (e.g., when blue light or tone was used for $\mathrm{CS}+$, a house light and white noise was used for $\mathrm{CS}-$, and vice versa). We initially evaluated the efficacy of the conditioning by assaying the number of nose pokes into a food well in response to the $\mathrm{CS}+$ vs. $\mathrm{CS}-$. We found that mice responded with nose pokes to the $\mathrm{CS}+$ trials $95 \%$ of the time by the last training session, vs. $30 \%$ of the time after exposure to the CS- (Two-way ANOVA: CS + vs CS

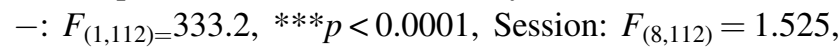
$p=0.1565$, Interaction: $F_{(8,112)}=2.199,{ }^{*} p=0.0326$, followed by Sidak's multiple comparison test: ***sessions 14-21: CS+ vs. CS-; Fig. 1b). In addition, mice retrieved and ate $100 \%$ of the delivered pellets after the sixth session indicating that the mice were motivated to eat during training (Supplementary Figure 1). Mice were then fed ad libitum for 5 days until their weight returned to baseline after which their food intake post exposure to the CS+ and $\mathrm{CS}-$ was tested. The training elicited a robust increase in feeding, as mice ate significantly more during the test in response to the CS + than to the CS $-\left(t\right.$ test, $t_{(14)}=3.93$, $* * p=0.0015$, Fig. 1c).

However, from start to finish, this training procedure took a total of 4 weeks using operant chambers, which limits the utility of this approach for generating the larger number of animals that would be required for molecular and functional studies of the neural circuit underlying the observed response. We thus tested whether we could shorten the length of time needed to condition animals by training mice to overeat in response to a specific context rather than in response to discrete cues.

We began by habituating ad libitum fed mice to two different novel contexts for one $20 \mathrm{~min}$ session each. The two contexts differed in size, shape, wall color and floor texture. In addition, the two contexts were located in different rooms so that the gross location of the room could not be generalized during testing (Fig. 1d, Supplementary Figure 1).

After the habituation session, one group of mice continued to be fed ad libitum, while another group of mice were fasted for $24 \mathrm{~h}$ prior to training. During the $30 \mathrm{~min}$ training sessions, mice were placed into one of the contexts $(\mathrm{Ctx}+)$ and were able to freely explore and obtain food from a food well. The unpaired context, in which food was not available, was designated as $\mathrm{Ctx}-$. Following each 


\section{a}

Food Restriction

Ad libitum
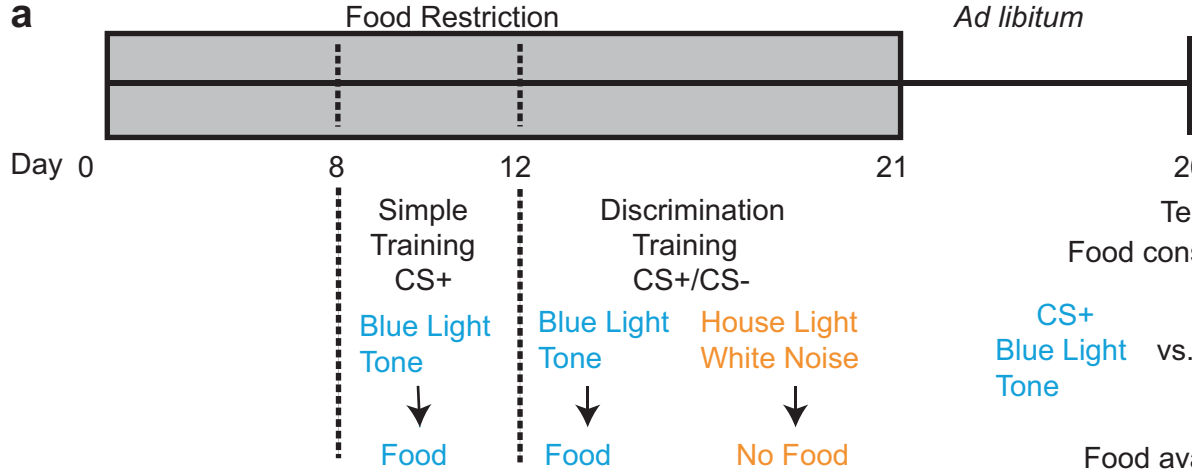

26

Test

Food consumption

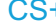

Blue Light vs. House Light
Tone

White Noise

Food available
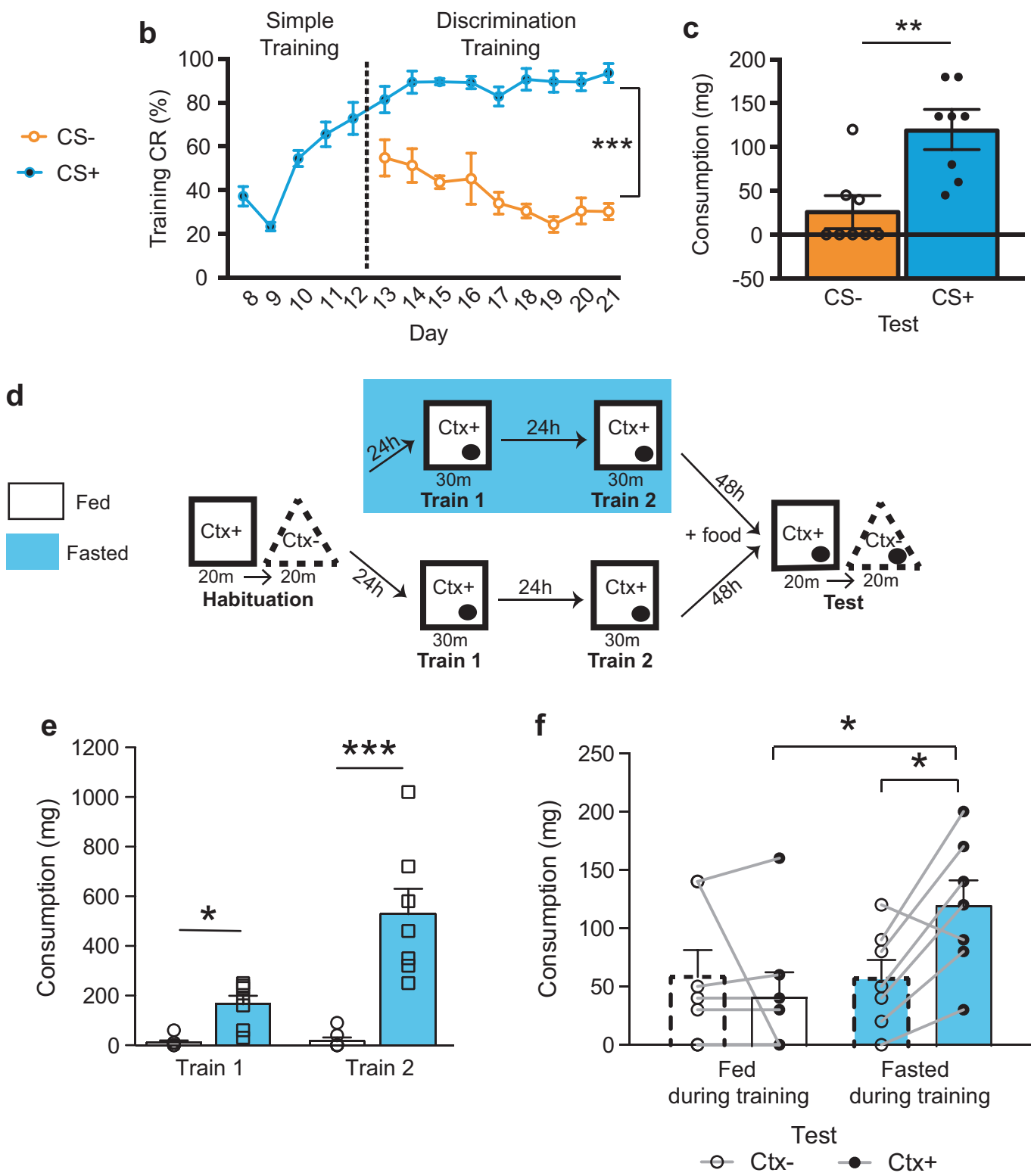

training session mice were returned to their home cages until the next training session. At the conclusion of this two day training period, the mice were fed ad libitum in their

home cages for two days after which they were tested by returning them, serially into each of the two different contexts $(\mathrm{Ctx}+$ and $\mathrm{Ctx}-)$ for twenty minutes in the presence 
4 Fig. 1 Cue-induced feeding paradigm (Cue-IF) and Context-induced feeding paradigm (Ctx-IF) similarly induce overeating in mice. We used an established Pavlovian conditioning paradigm to induce increasing food consumption in sated mice in response to discrete sensory cues (e.g., light and tone) and a novel paradigm utilizing contextual cues to induce a similar response. a Experimental schedule of Cue-IF. Mice were restricted to $85 \%$ body weight (represented by the gray box) from day 0 to day 7 and were conditioned in 2 phases. Phase 1 (Day 8-12) consisted of pairing a tone + light with food delivery $(\mathrm{CS}+$ ). Phase 2 (Day 13-21) consisted of continuing the original pairing while adding in a second tone + light combination that is not paired with food (CS-). After testing, mice were returned to ad libitum feeding and were then tested for their food consumption in response to both the $\mathrm{CS}+$ and $\mathrm{CS}-$. b Nose pokes into the food well in response to the conditioned stimulus $(\mathrm{CS}+$ ) compared to nose pokes in response to the unconditioned stimulus (CS-) during training (Days 9-21). The conditioned response (CR) is represented as the percentage (\%) of trials in which animals make a nose poke into the food port in response to the $\mathrm{CS}+$ or $\mathrm{CS}-$. c During testing, the food intake (represented in milligrams, mg) after exposure to CS - and CS + was compared in sated mice, showing a significant increase in response to the conditioned stimulus $(\mathrm{CS}+)$. a-c $N=7-8$. d Experimental schedule of Ctx-IF. Mice were habituated to two different novel contexts and then separated into two groups, one fasted overnight (blue) and one that continued to be fed ad libitum (white). They were then trained in one of the two contexts $(\mathrm{Ctx}+)$ with food available. After 2 training sessions, all mice were returned to ad libitum feeding for $48 \mathrm{~h}$ and were then tested for their food consumption in response to exposure to both the context which had been paired with food during training (Ctx $+)$ and the unpaired context $(\mathrm{Ctx}-)$. e The food intake (represented in milligrams, $\mathrm{mg})$ in response to the paired context $(\mathrm{Ctx}+)$ during training, comparing mice that were fasted prior to training (blue bars) and mice that were fed ad libitum (white bars). f During testing, the food intake after exposure to $\mathrm{Ctx}-$ and $\mathrm{Ctx}+$ was compared in both mice that were fasted prior to training and mice that were fed ad libitum. This shows a significant increase in response to the paired context $(\mathrm{Ctx}+)$ as compared to the unpaired context $(\mathrm{Ctx}-)$, only in mice that were fasted prior to training. d-f $N=7-8$. $* P<0.05$, $* * P<$ $0.001, * * * P<0.001$

of food. They were again able to freely explore and obtain food from the food well. We refer to this paradigm as context-induced feeding (Ctx-IF).

A comparison of the food consumption during the training sessions revealed a significant increase in food intake in the mice fasted prior to training compared to the mice that had been fed prior to training (i.e; "Fed" controls; two-way ANOVA: Fed vs. Fasted: $F_{(1,12)}=31.47$, *** $p=$ 0.0001 , Test 1 vs. Test 2: $F_{(1,12)}=14.29$, ***p $=0.0026$, Interaction:: $F_{(1,12)}=13.21$, ***p $=0.0034$, followed by Sidak's multiple comparison test: ***Train 2: Fed vs. Fasted, ***Fasted: Train 1 vs. Train 2; Fig. 1e). As expected, during testing, these Fed control animals ate only a small, similar amount in both $\mathrm{Ctx}+$ (the environment where food was available during training) and $\mathrm{Ctx}-$ (the environment where food was not available during training). In contrast, sated mice that had been fasted prior to training ate significantly more when placed in $\mathrm{Ctx}+$ than in $\mathrm{Ctx}-$ during testing (two-way ANOVA: Fed vs. Fasted: $F_{(1.12)}=$ 2.255, $\quad p=0.1591, \quad \mathrm{CS}: \quad F_{(1.12)}=2.738, \quad p=0.1239$,
Interaction: $F_{(1,12)}=7.797, \quad * p=0.0163$, followed by Sidak's multiple comparison test: *Fasted: CS+ vs. CS-, $* \mathrm{CS}+$ : Fasted vs. Fed; Fig. 1f). Moreover, the food intake in $\mathrm{Ctx}+$ was similar to that observed in mice responding to the $\mathrm{CS}+$ using the standard cue-induced feeding protocol described previously (see Fig. 1a). In addition, the mice that had been fasted prior to training consumed very little food when placed in $\mathrm{Ctx}-$; indeed, it was equivalent to the amount that Fed control mice consumed in Ctx - (Fig. 1f). The observation that the fully trained animals, when refed, failed to increase intake when placed in the Ctx - environment, indicates that the increased intake in $\mathrm{Ctx}+$ was not being driven by hunger during the test itself and rather from the learned association of this environment with privation. The order of context in which mice were habituated and tested was counterbalanced to ensure that the order of testing was not a factor in the amount of food consumption. Overall this protocol showed similar efficiency to cueinduced Pavlovian feeding despite the fact that the satisfactory completion of a training protocol sufficient to induce an overeating response required a total of 5 days, and just 2 training sessions for Ctx-IF compared to an average of 1 month and 14 daily training sessions to condition animals using the cue-induced feeding protocol.

\section{Parameters influencing context-induced feeding}

Performance of learning and memory tasks can be affected by even subtle differences in specific aspects of the training paradigm. We thus tested whether varying the length of time between training sessions (e.g., spaced vs. massed training over short periods of times) influenced the robustness of the conditioning, as has been demonstrated for other paradigms [18]. We first tested whether increased food intake after exposure to a specific context could be generated by massed training, in which the training is conducted in two sessions in a single day. Mice were habituated and fasted overnight and were then trained in two Ctx-IF sessions with an interval of $5 \mathrm{~h}$ between them (Fig. 2a). As expected, the fasted mice consumed more food during training (Fig. 2b), but when they were later tested in the fed state, they failed to show a difference in food intake between the $\mathrm{Ctx}+$ and the $\mathrm{Ctx}-\left(t\right.$ test: $t_{(14)}=0.097, p=$ 0.925; Fig. 2c). We then asked whether the massed protocol would be sufficient to induce overconsumption if there was increased motivation to consume during training. We trained the mice as described above, but after habituation, now fasted them for $48 \mathrm{~h}$ instead of $24 \mathrm{~h}$ (Fig. 2d). Again, we saw that although they ate more during training (Fig. 2e), the mice failed to show a difference in food intake between $\mathrm{Ctx}+$ and $\mathrm{Ctx}-$ during testing $\left(t\right.$ test: $t_{10}=1.208$, $p=0.2549$; Fig. 2f) despite the longer period of food restriction and associated increase in motivation. We 

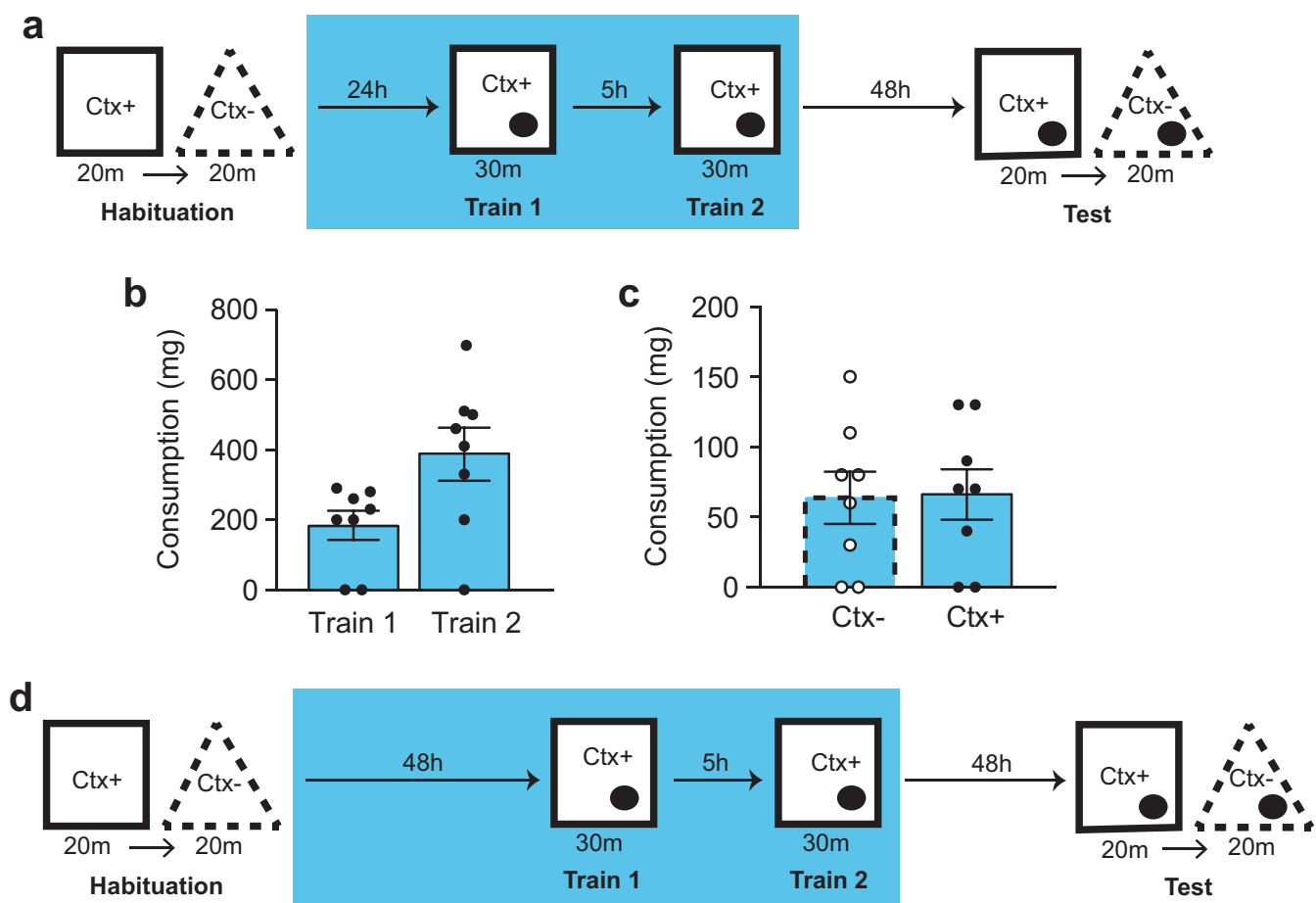

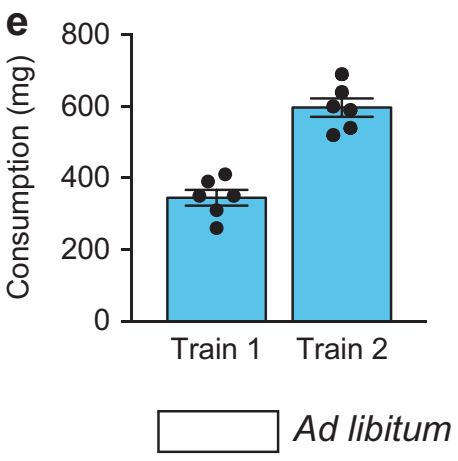

Fig. 2 Massed training is not effective to induce context-dependent overconsumption. The impact of massed training trials during Ctx-IF was evaluated. a Experimental schedule. Mice were habituated and trained as described, but with the 2 training sessions conducted in one day, separated by $5 \mathrm{~h}$. b The food intake (represented in milligrams, $\mathrm{mg})$ in response to the paired context $(\mathrm{Ctx}+)$ during training in mice that were fasted prior to training. $\mathbf{c}$ During testing, the food intake after exposure to $\mathrm{CS}-$ and $\mathrm{CS}+$ was compared in mice. There was no increase in response to the paired context $(\mathrm{Ctx}+)$ as compared to the

therefore concluded that massed training conducted over 1 day is not sufficient to induce overeating, regardless of the motivational state of the animal.

We then tested the robustness of the conditioning when the two training sessions were conducted $24 \mathrm{~h}$ apart, or longer. As before, mice were habituated and fasted overnight, after which the first training session in $\mathrm{Ctx}+$ was conducted. The mice were then fed ad libitum for $24 \mathrm{~h}$ after which they were again fasted overnight followed by a second training session in $\mathrm{Ctx}+$. In total, $48 \mathrm{~h}$ separated the two training sessions. Mice were then returned to ad libitum

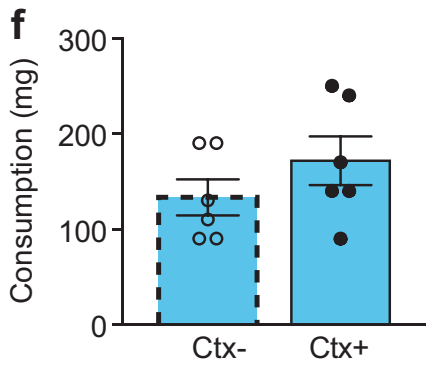

Fasted

unpaired context $(\mathrm{Ctx}-)$. a-c $N=8$. d Experimental schedule. Mice were habituated and trained as described, but were fasted for $48 \mathrm{~h}$ prior to the massed training protocol. e The food intake (represented in milligrams, mg) in response to the paired context $(\mathrm{Ctx}+)$ during training in mice that were fasted prior to training. $\mathbf{f}$ During testing, the food intake after exposure to $\mathrm{CS}-$ and $\mathrm{CS}+$ was compared in mice. There was no increase in response to the paired context $(\mathrm{Ctx}+)$ as compared to the unpaired context $(\mathrm{Ctx}-)$. $\mathbf{d}-\mathbf{f} N=6$

food access for two days. The food intake in the sated mice was then compared in $\mathrm{Ctx}+$ vs $\mathrm{Ctx}-$ (Fig. 3a). During training, fasted mice ate significantly more than fed controls (two-way ANOVA: Training Session: $F_{(1,6)}=4.5, p=$ 0.0781 , Fed vs. Fasted: $F_{(1,6)}=21.74, * * p=0.0035$, Interaction: $F_{(1,6)}=4.5, p=0.0781$; Fig. $\left.3 b\right)$. During testing, mice who had been fasted during training consumed significantly more food in response to the training context, Ctx + , than to the Ctx - (two-way ANOVA: Ctx: $F_{(1,6)}=$ $29.99, * * p=0.0015$; Fasted vs Fed: $F_{(1,6)}=10.22, * p=$ 0.0187; Interaction: $F_{(1,6)}=11.02, * p=0.0160$, followed 
Fig. 3 Spaced training reliably induces context-dependent overconsumption. a Experimental schedule. Mice were habituated and trained as described, but Fasted mice (top) were trained with 2 sessions, separated by $48 \mathrm{~h}$ and were given ad libitum access for $24 \mathrm{~h}$ after training session 1. Fed controls (bottom) were trained at the same time without any prior food deprivation. b The food intake (represented in milligrams, $\mathrm{mg}$ ) in response to the paired context $(\mathrm{Ctx}+)$ during training, comparing mice that were fasted prior to training sessions (blue bars) and mice that were fed ad libitum (white bars). c During testing, the food intake after exposure to $\mathrm{Ctx}-$ and $\mathrm{Ctx}+$ was compared in both mice that were fasted prior to training and mice that were fed ad libitum. This shows a significant increase in response to the paired context $(\mathrm{Ctx}+)$ as compared to the unpaired context $(\mathrm{Ctx}-)$, only in mice that were fasted prior to training. $N=4 . * * P<0.01, * * * P<0.001$
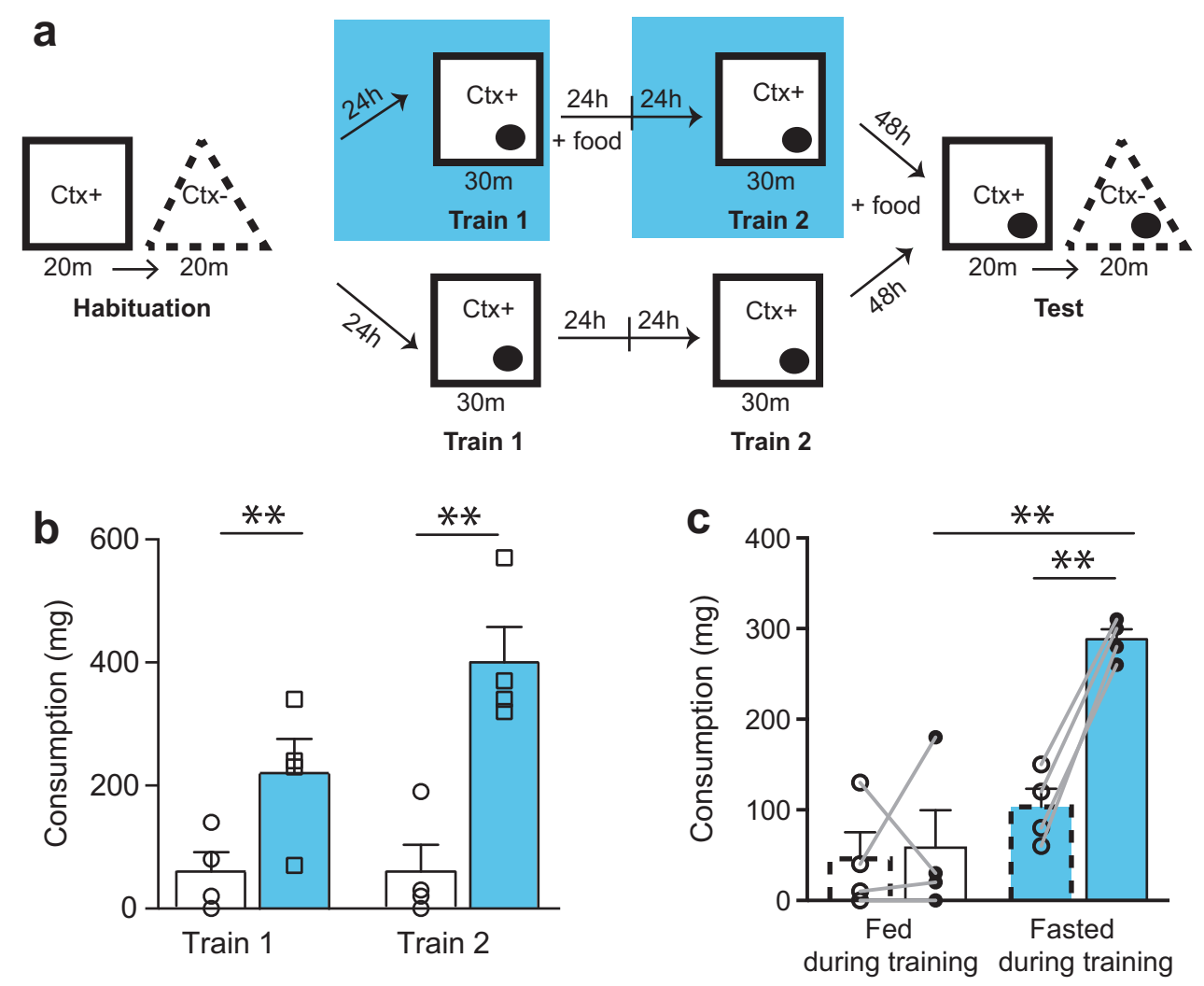

Ad libitum

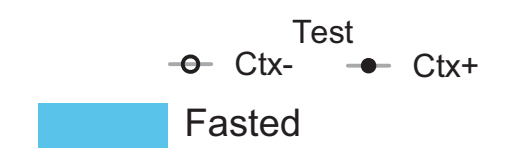

by Sidak's multiple comparison test: $* * \mathrm{CS}+/-$ fasted vs. fed, **fasted-CS+ vs. CS-; Fig. 3c). As before, mice that had been fed during the training sessions ate only a small amount of food, in similar amounts, in the two environments, $\mathrm{Ctx}+$ and $\mathrm{Ctx}-$. These data show that massed training in a single day is not effective, while conducting the training trials over an interval of at least $48 \mathrm{~h}$ generates a robust association between the training $\mathrm{Ctx}+$ and food intake in sated mice.

\section{Context-induced feeding has components of negative and positive valence}

We next asked whether the increased food intake in the conditioned animals' response was driven primarily by negative valence (e.g., hunger) or positive valence (e.g., food reward). We hypothesized that if the conditioned behavior (food intake) was driven primarily by food reward (and not by hunger), mice that were fasted and then trained in the $\mathrm{Ctx}+$ without receiving food there (negative valence group, Fig. 4a, middle) would not show potentiated feeding during testing sessions. In contrast, if the response was driven primarily by hunger, the negative valence group would still show a potentiated feeding response in a subsequent testing session, similar to mice that were given food during the training sessions in $\mathrm{Ctx}+$, as described above (positive valence group, Fig. 4a, top).

Body weight did not differ between groups before training or during habituation (Supplementary Figure 2). As expected, body weight of both the positive and negative valence groups, which were fasted, dropped significantly during the training protocol. During training, fed controls (Fig. 4a, bottom) ate very little, while the positive valence group, which is trained with food available in the training context, ate significantly more during training, as they did in previous experiments (Two-way ANOVA: ***Train 1 vs 2: $F_{(1,23)}=34.86, P<0.0001$, ***Fed vs. Fasted: $F_{(1,23)}=$ 49.31, $P<0.0001$, ***Interaction: $F_{(1,23)}=34.86$, followed by Sidak's multiple comparison: ***Train 1: fed vs. positive, ***Train 2: fed vs. positive; Fig. 4b). The negative valence group was trained without food and therefore no consumption measurement was made during training sessions. However, the mice were then given amounts of food paired to that of the fasted group during the intertrial intervals to ensure that their metabolic status was equivalent to the positive control group (Fig. $4 \mathrm{~b}$, right). Body weight of both the positive and negative valence groups returned to normal within the first $24 \mathrm{~h}$ after training and remained 
Fig. $4 \mathrm{Ctx}$-IF is driven primarily by positive reinforcement. The role of hunger vs food reward to drive increased consumption during Ctx-IF testing was tested. a Experimental schedule. Positive valence mice (top, blue) were fasted prior to training and trained with food available as described, whereas negative valence mice (middle, gray) were fasted prior to training, but trained without food availability. Fed controls (bottom) were trained with food availability, but were not fasted prior to training, as described. b The food intake (represented in milligrams, $\mathrm{mg}$ ) in response to the paired context $(\mathrm{Ctx}+)$ during training, comparing mice that were fasted prior to training sessions (Positive valence mice, blue) and mice that were fed ad libitum (Fed controls, white). Paired amounts of food were given to the negative valence group (gray). c During Test 1, the food intake after exposure to $\mathrm{Ctx}-$ and $\mathrm{Ctx}+$ was compared in positive valence mice, negative valence mice and fed controls. Positive valence mice consume significantly more than fed controls and negative valence mice in response to $\mathrm{Ctx}$ + during testing. d During Test 2 the food intake after exposure to $\mathrm{Ctx}-$ and $\mathrm{Ctx}+$ was compared in positive valence mice, negative valence mice and fed controls. Positive valence mice consume significantly more than fed controls and negative valence mice in response to $\mathrm{Ctx}+$ during testing. $N=7-8 . * P<0.05, * * P<0.01$, $* * * P<0.001$
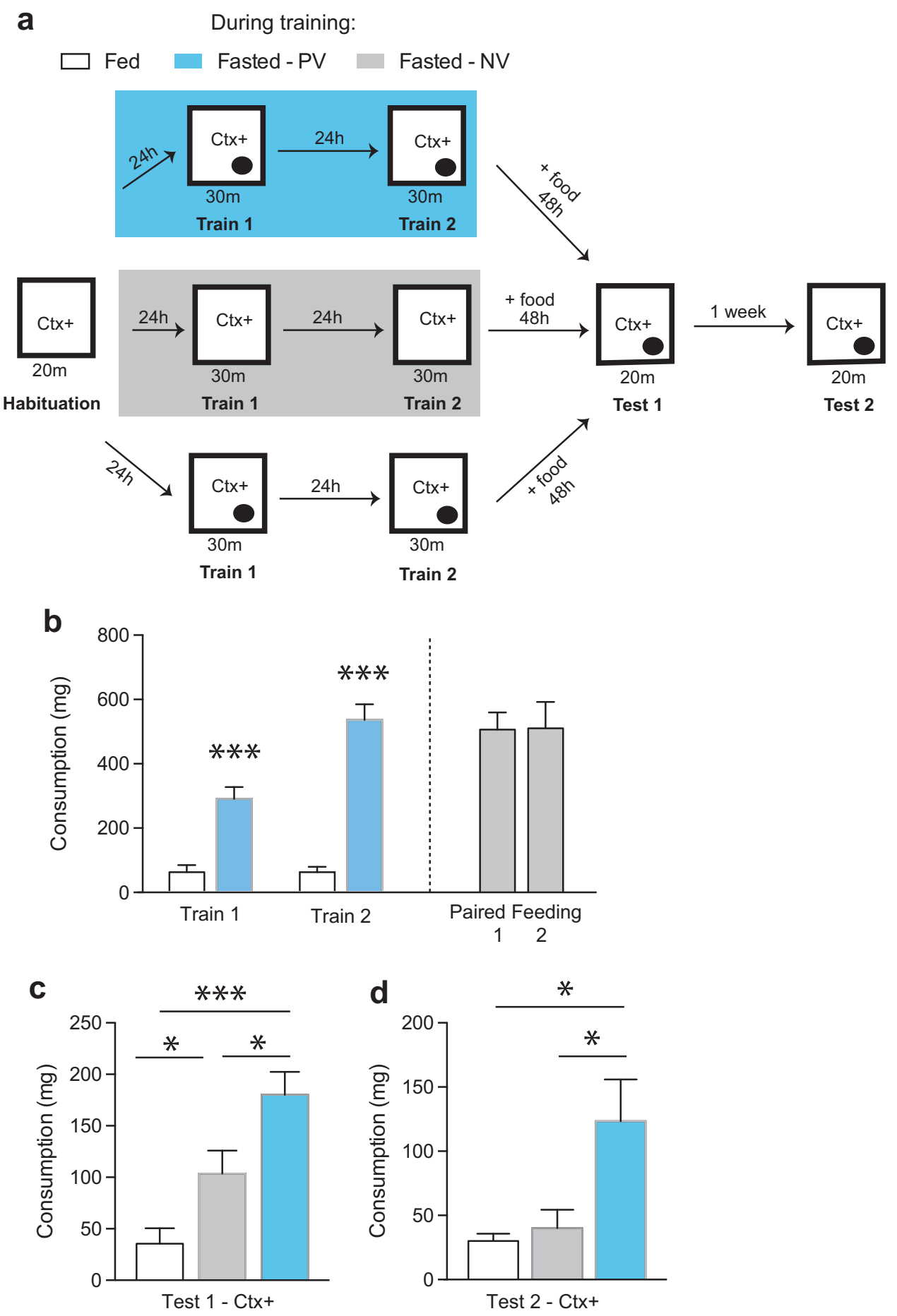

comparable to the fed control group by the time of the first testing session (Supplementary Figure 2). As expected, fed controls consumed only a small amount of food in Ctx + during the testing session. In contrast, the positive valence group that was fasted prior to training and then given access to food in the $\mathrm{Ctx}+$ during training, ate significantly more in the $\mathrm{Ctx}+$ than the fed controls during testing (Fig. 4c), as in previous experiments (see Figs. 2 and 3). Interestingly, mice in the negative valence group exhibited an intermediate effect. While they ate significantly more than the fed controls in response to the $\mathrm{Ctx}+$, they consumed significantly less food than the mice in the positive valence group (one-way ANOVA; $F_{(2,36)}=11.34$, *** $p=0.0002$, followed by Neuman Keul's multiple comparison test: $* * *$ Fed vs. Positive, *Positive vs. Negative; *Fed vs. Negative; Fig. 4c). Furthermore, when we tested these 
animals again 1 week later, mice in the positive valence group still ate significantly more than both the fed controls and the negative valence group, but mice in the negative valence group no longer consumed more than the fed controls (one-way ANOVA: $F_{(2,13)}=4.891, * p=0.0261$, followed by Neuman Keul's multiple comparison test: *Fed vs. Positive, *Positive vs. Negative; Fig. 4d), indicating that the memory that drives overconsumption is both driven by reward and is long-lasting. We therefore concluded that, although negative valence contributes to the potentiated feeding response, the maximal response is driven by the reward value of food received during training sessions and the effect of positive valence is more durable.

\section{Mapping of brain regions activated by context- induced feeding}

We next determined which brain regions are activated by $\mathrm{Ctx}+$ in conditioned animals using immediate early gene mapping with cFos as a marker for neural activation [19]. As described above, fasted mice were trained to associate food with a specific context, then refed and euthanized 30 min after placement in $\mathrm{Ctx}+$ during the test. Another group of naïve mice that were not trained, but were euthanized at the same time as the $\mathrm{Ctx}+$ group, served as controls and a third group was exposed to the unpaired context $(\mathrm{Ctx}-)$ during the test before being euthanized (Fig. 5a). We then performed immunohistochemistry using cFos to compare its levels in $\mathrm{Ctx}+$ mice to $\mathrm{Ctx}-$ mice and Naïve controls. In this analysis we focused on higher-order brain regions because of the known functional relationship of several cortical and subcortical structures with learning and memory. We found that subpopulations of neurons in the following brain regions are activated after exposure to the $\mathrm{Ctx}+$ compared to the control groups, including the insular cortex (IC), central amygdala, lateral septum and lateral hypothalamus ( $t$ test, insular cortex: $t_{2}=2.4, * p=0.0221$, central amygdala: $t_{2}=5.277, * p=0.0341$, lateral septum: $t_{2}=6.656, * p=0.0218$, lateral hypothalamus: $t_{2}=7.992$, $* p=0,0153$, Fig. $5 b$ ). Each of these brain regions has been previously shown to play a role in the control of food intake [20-28]. Conversely, in the paraventricular thalamus, we observed increased cFos in Ctx - compared to $\mathrm{Ctx}+(t$ test: $t_{2}=2.854,{ }^{*} p=0.0462$, Supplementary Figure 3 ). In the basolateral amygdala we found significant, but equivalent, cFos staining in both the Ctx + and Ctx $-\left(t\right.$ test: $t_{2}=$ $0.1153, p=0.9918$ ), while a number of regions showed very little cFos in any condition, including $\mathrm{S} 1$ and the caudate putamen (Supplementary Figure 3). Although naïve mice displayed almost no cFos staining in almost all of these regions, they did exhibit prominent $\mathrm{cFos}$ staining in other regions such as the dentate gyrus (Supplementary Figure 4).
We found the insular cortex to be of particular interest because a previous study suggested that the insula projects to multiple efferent sites that play a role in feeding [29]. A detailed analysis of the $\mathrm{cFos}$ staining throughout the insular cortex revealed that although the number of $\mathrm{cFos}+$ cells was significantly increased in the $\mathrm{Ctx}+$ group compared to Ctx - overall, post-hoc comparisons did not reveal any particular regions of the insular cortex to be significantly enriched (Supplementary Figure 5). We therefore chose to inactivate the insular cortex in approximately the middle of its $\mathrm{A} / \mathrm{P}$ axis $(+0.26 \mathrm{~A} / \mathrm{P}$ from bregma) and test its role in Ctx-IF, using the GABA agonists, muscimol and baclofen. Mice were trained as described to exhibit Ctx-IF and $20 \mathrm{~min}$ before testing were injected with either saline or a combination of muscimol and baclofen, directly into the IC (Fig. 5c). We found that mice injected with saline ate more in the $\mathrm{Ctx}+\mathrm{vs}$. the $\mathrm{Ctx}-$ environment, as expected. In contrast, mice in which the insular cortex was inhibited just prior to training did not overeat and instead consumed the same amount of food in $\mathrm{Ctx}+$ as saline-injected mice did in Ctx - (one-way ANOVA, $F(1,6)=21.74, * * p=0.0098$, followed by Neuman Keul's multiple comparison Test: *Saline-Ctx- vs. Saline Ctx+ ; *Saline-Ctx + vs. Muscimol/ Baclofen-Ctx+; Fig. 5d). Overall these data suggest that neurons in the insular cortex are activated when animals are trained to associate cues with food availability and that proper functioning of this region is required for the development of this association.

\section{Discussion}

Feeding is a complex motivated behavior and in recent years numerous neural circuits that regulate the homeostatic control of ingestion have been identified [30, 31]. However, feeding can also be influenced by external cues that predict food availability and it is well established that Pavlovian conditioning of animals can lead to increased food intake even in fed, satiated animals [9-11]. However, in contrast to the substantial progress that has been made in understanding the neural mechanisms that control homeostatic feeding, our understanding of the mechanisms that control cue-induced feeding is limited. The importance of delineating the mechanisms responsible for this behavior is important because cue-induced overeating has been demonstrated repeatedly in overweight and obese human subjects and may also underlie aspects of compulsive eating and binge-eating disorder [32, 33]. We thus set out to develop a robust assay for eliciting behavioral conditioning of feeding in mice with the aim of identifying neural sites that play a role in the genesis of this behavior. Here we report the validation of a rapid and robust protocol for context-induced feeding in mice and its use to identify brain 
a

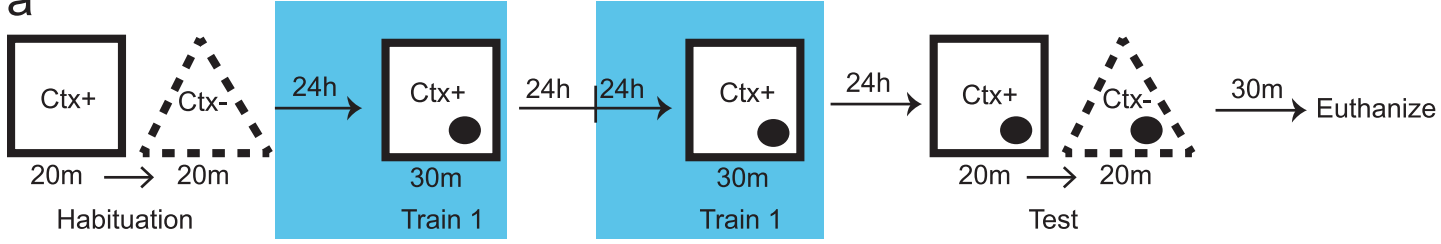

b

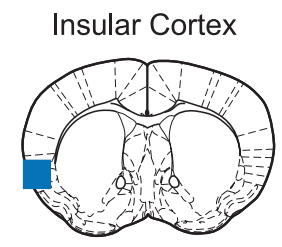

Lateral Hypothalamus

Central Amygdala

Lateral Septum
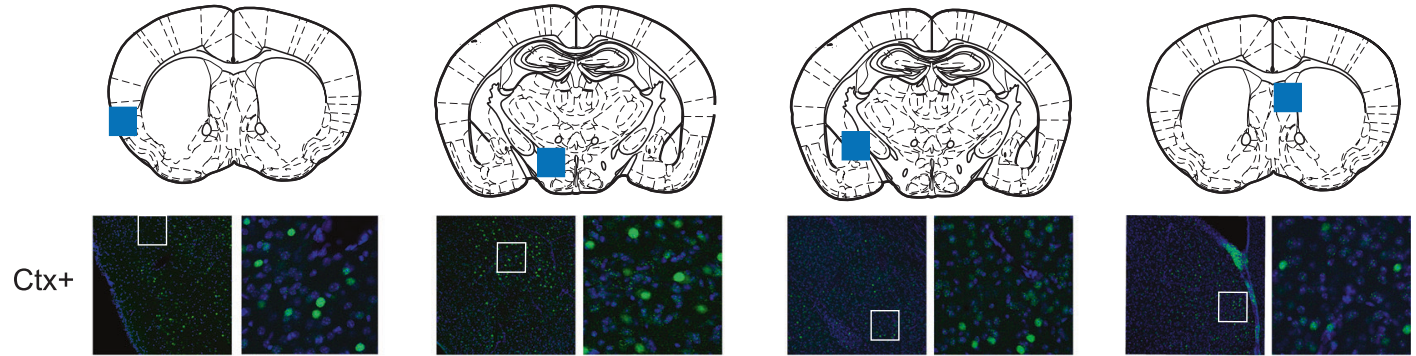

Ctx-
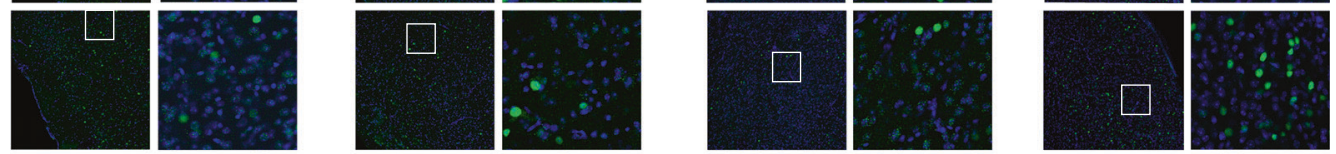

Naive
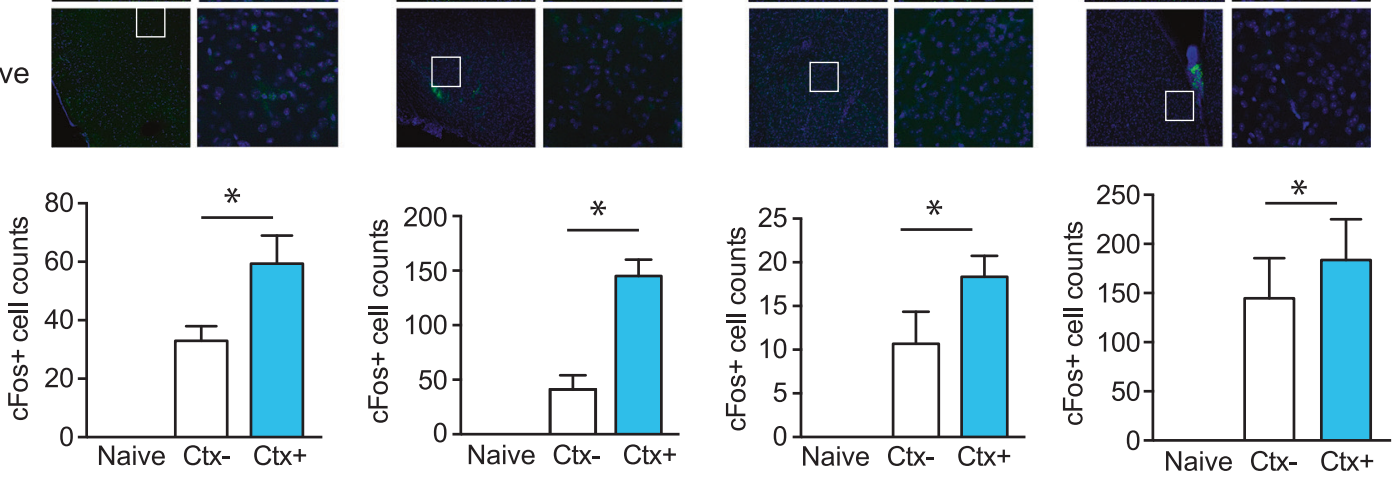

C
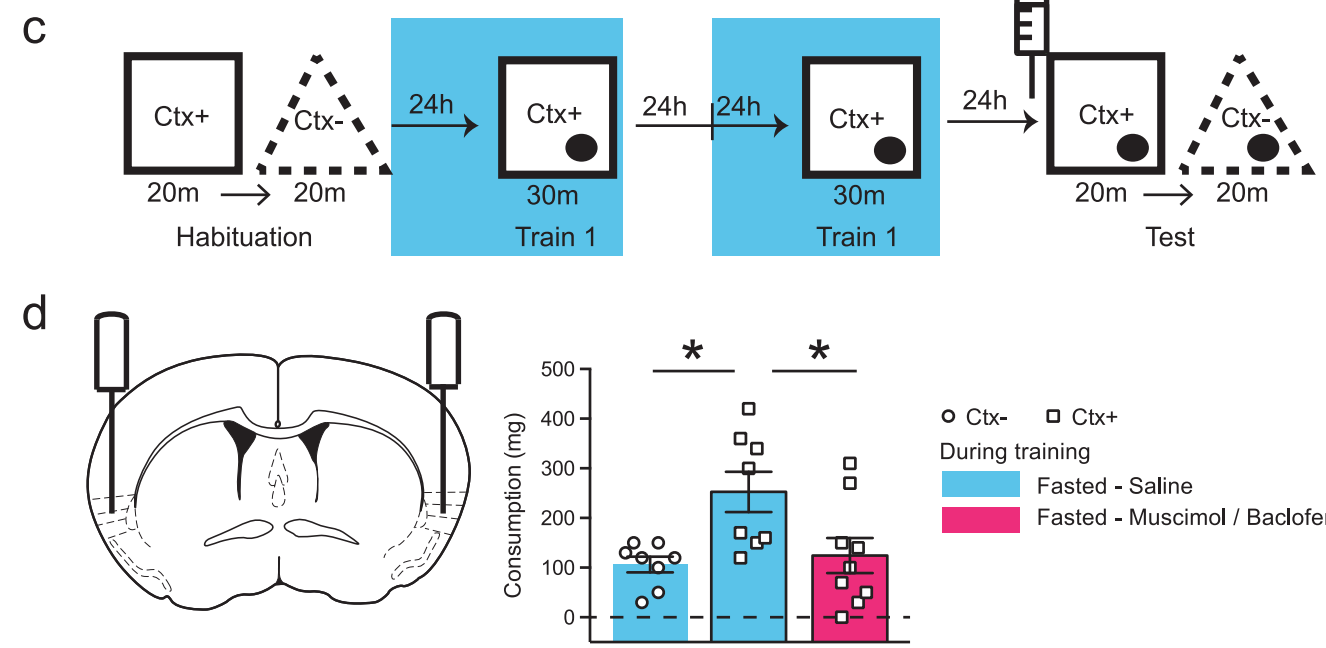

- Ctx- $\square \mathrm{Ctx}+$ During training

Fasted - Muscimol / Baclofen

regions that are activated by the conditioning stimulus, which is a specific context. We also provide evidence that normal functioning of the insular cortex is required for the development of this response.
Current paradigms in use as models of overeating are of limited utility for studying associative mechanisms that convey food reward and lead to increased food consumption. For example, diet-induced obese mice (DIO) only have 
Fig. $5 \mathrm{Ctx}$-IF activates the insular cortex, which is required for overconsumption. The anatomic loci activated in response to the paired context $(\mathrm{Ctx}+)$ and unpaired contex $(\mathrm{Ctx}-)$ were mapped. a Experimental schedule. Mice were habituated and trained as described, and were then euthanized $30 \mathrm{~min}$ following Ctx-IF testing. b Increased activation as measured by cFos (green) in the insular cortex, lateral septum, central amygdala and lateral hypothalamus in mice, following ctx-IF testing in Ctx + (top), compared to Ctx - (middle) and Naïve mice (bottom). DAPI is stained in blue. White inset boxes are magnified to the right. $N=3$. c Experimental schedule. Mice were habituated and trained as described, but were injected with saline or muscimol/baclofen solution $15 \mathrm{~min}$ before Ctx-IF testing into the insular cortex. d During testing, food intake was compared in fasted mice who were either injected with saline (blue) or muscimol/baclofen (pink) prior to the testing session. Saline-injected mice consume significantly more in response to $\mathrm{Ctx}+$ than $\mathrm{Ctx}-$. In contrast, fasted mice injected with muscimol/baclofen (pink) eat significantly less in the $\mathrm{Ctx}+$ than saline-injected mice. $N=8-9 . * \mathrm{P}<0.05$

access to a high fat diet (HFD) [34], and thus learning is not tested in this model. Other studies have examined the mechanisms underlying cue-induced instrumental responses, that is, the act of obtaining a food reward predicted by a specific sensory cue $[35,36]$. However, these studies typically examine mice that are food-restricted and are therefore highly motivated to seek a food reward. Thus, because these mice are only tested when hungry, it is difficult to disentangle the contribution of homeostatic feeding in these assays.

As an alternative, several groups have shown that cueinduced feeding can be used to study increased consumption in sated subjects. Unfortunately, also shown here, the task requires extensive training over a long period of time, thus limiting its utility for using optogenetics or equivalent methods to dissect the neural mechanisms that control this set of responses. This is because optogenetic and chemogenetic methods to modulate neural activity require that one perform stereotaxic surgeries ( 1-2 week for recovery) with viral injections ( 2-4 weeks for viral expression) further extending the time required to complete a study. In addition, the limited throughput using operant chambers in a cueinduced feeding protocol also makes it difficult to generate a sufficiently large cohort of animals. We therefore set out to employ a version of this task that offered greater throughput and less extensive training with which to study the mechanisms and circuitry underlying conditioned overeating. We reasoned that since context is associated with defined sensory inputs, it would be possible to assign motivational salience to a specific environment (referred to as $\mathrm{Ctx}+$ ) rather than the use of discrete cues. The utility of context as an associative stimulus for feeding in sated mice was validated even when using a protocol that employed few as 2 training sessions over 2 days. Shorter training periods however were not effective for inducing food intake in fed mice. That spaced training is more effective than massed training is consistent with the vast majority of learned behaviors [37-39]. Thus, we showed that two training sessions conducted $5 \mathrm{~h}$ apart was not sufficient to induce increased consumption during the $\mathrm{Ctx}-\mathrm{IF}$ test. The failure of the trained mice to eat more in the testing session did not appear to be due to decreased hunger during the second training session, as there was no statistical difference between food consumption during the two training sessions. Indeed, in all the experiments, mice in fact tended to eat more during the second training session, indicating that they have already begun to learn the significance of the context by the second session.

Food intake can be driven either by the relief of negative valence (ie. the unpleasant experience of hunger) or by positive valence, which refers to the reinforcing or reward value of food [40, 41]. We thus tested whether the increased intake of food in sated mice after training was driven by positive or negative valence. We found that, in ctx-IF, the maximal consumption response is driven primarily by reward, as mice given food during training (positive valence) eat significantly more in response to the $\mathrm{Ctx}+$ compared to Fed controls and to mice trained without the food reward (negative valence). Recent studies have suggested that activation of AGRP neurons in the hypothalamus increases feeding by conveying negative valence (that is alleviated by feeding) [42] and can indirectly induce feeding via indirect projections to the insular cortex, [43] which we show contributes to this behavior. Because we saw that the negative valence group eats an intermediate amount of food, these results raise the possibility that mice overeat in response to the $\mathrm{Ctx}+$ in part because the context reminds them of the unpleasant sensation of hunger that was previously experienced in that environment. However, because this group did not eat as much as animals who received food during training, this suggests that the maximal increased feeding response is also driven by the pleasure derived from the food received there (positive valence).

What then are the neural mechanisms underlying nonhomeostatic eating? In this study we used cFos as a marker of neural activity to determine which brain regions are activated following Ctx-IF. We found that a number of cortical and subcortical brain regions including insular cortex, central amygdala, lateral septum and lateral hypothalamus were activated in sated animals placed into the $\mathrm{Ctx}+$. These findings are consistent with a previous study that measured cFos induction during and after the training portion of a Cue-IF [44] paradigm. This paper also reported that cFos induction differed significantly between early and late training sessions in a number of forebrain regions including infralimbic and prelimbic, insular cortex, dorsomedial striatum, and hypothalamus (lateral and paraventricular) in tone-food paired groups. In contrast, we performed an unbiased screen of brain regions activated by 
context in sated mice after training had been completed and the association had been fully established. The brain regions we identified in this manner partially overlapped with those identified during training including the insular cortex, as well as the amygdala and lateral septum. We also found activation of the lateral hypothalamus $(\mathrm{LH})$, which is consistent with the finding that the mice consume more food. This finding is also consistent with neural tracing studies using pseudo-rabies virus (PRV) to map brain regions synaptically connected to peripheral areas controlling motor and autonomic aspects of feeding [29]. The insular cortex was one of a small number of brain regions that were common to the descending neural circuits projecting to all of the peripheral sites, indicating that it is likely involved in an integrative function in generating feeding behavior [29]. Although some studies suggest different functional roles for rostral and caudal insular cortex, we did not see any subregional differences when we examined cFos levels after Ctx-IF.

While cFos is a reliable marker for neural activation, it does not provide any insight into the specific neural populations involved in generating the behavior. Recently, PhosphoTRAP, a method that can be used to profile neurons activated by a specific stimulus, has been developed, thus making it possible to identify the specific neural subpopulations that are activated by the conditioned stimulus (i.e; context) [45]. The identification of markers for the activated neurons in the aforementioned brain regions will enable testing of their function and the ways in which these higher-order circuits interact with brain regions that control homeostatic feeding. Another recently developed immunoprecipitation method can also be used to determine precisely the neural populations that connect to these homeostatic centers [46]. Both of these methods are currently being used to define the neural populations that are specifically activated by context in trained animals and that project to homeostatic centers.

Finally, we also used GABA agonists, muscimol and baclofen, to test whether the insular cortex is necessary for the development of Ctx-IF. We chose to focus on the insular cortex because of the observation that it indirectly projects to multiple efferent sites that are activated during feeding. In addition, the IC receives projections from the basolateral amygdala, which is critical for associative learning and the IC also sends projections to the central amygdala, lateral hypothalamus and nucleus accumbens, brain regions that are also known to impact feeding behavior [47-50]. Furthermore, other studies have also shown that the insular cortex is required for learning cue-reward associations [43, 51]. However, a direct role in overconsumption for the IC has not yet been demonstrated and other studies using GABA agonists have failed to show a role for the insular cortex to control homeostatic feeding [43, 52]. Thus our results suggest a role for the insular cortex in identifying cues that predict food availability potentially accounting for binge-like episodes in response to those cues.

In summary, we have developed a context-induced feeding assay that can be rapidly and efficiently employed to condition mice to eat more in response to specific environmental cues. We used this task to study brain circuits that are activated during conditioning and further provide evidence for a functional role of the insular cortex. These findings will provide the basis for future experiments to identify the specific neural populations and establish their function as well as the neural connections through which they exert this effect.

Acknowledgements This work was supported by grants from the US National Institute of Health (F32-DK107077 to S.A.S) and the JBC Foundation to J.M.F. The study was conceived and designed by S.A.S and J.M.F. Experiments were conducted by S.A.S, K.R.D. E.P.A and E.S. The manuscript was written by S.A.S and J.M.F. with comments from all authors. The authors declare no competing financial interests. We thank the staff of the CBC at the Rockefeller University for technical support.

\section{Compliance with ethical standards}

Conflict of interest The authors declare that they have no conflict of interest.

Open Access This article is licensed under a Creative Commons Attribution 4.0 International License, which permits use, sharing, adaptation, distribution and reproduction in any medium or format, as long as you give appropriate credit to the original author(s) and the source, provide a link to the Creative Commons license, and indicate if changes were made. The images or other third party material in this article are included in the article's Creative Commons license, unless indicated otherwise in a credit line to the material. If material is not included in the article's Creative Commons license and your intended use is not permitted by statutory regulation or exceeds the permitted use, you will need to obtain permission directly from the copyright holder. To view a copy of this license, visit http://creativecommons. org/licenses/by/4.0/.

\section{References}

1. Volkow ND, Wise RA. How can drug addiction help us understand obesity? Nat Neurosci. 2005;8:555-60.

2. Flegal KM, Carroll MD, Kit BK, Ogden CL. Prevalence of obesity and trends in the distribution of body mass index among US adults, 1999-2010. JAMA. 2012;307:491-7.

3. Ogden CL, Yanovski SZ, Carroll MD, Flegal KM. The epidemiology of obesity. Gastroenterology. 2007;132:2087-102.

4. Farooqi IS, O'Rahilly S. Monogenic obesity in humans. Annu Rev Med. 2005;56:443-58.

5. Zheng H, Berthoud H-R. Neural systems controlling the drive to eat: mind versus metabolism. Physiology. 2008;23:75-83.

6. Berridge KC, Ho C-Y, Richard JM, DiFeliceantonio AG. The tempted brain eats: pleasure and desire circuits in obesity and eating disorders. Brain Res. 2010;1350:43-64.

7. Ziauddeen H, Alonso-Alonso M, Hill JO, Kelley M, Khan NA. Obesity and the neurocognitive basis of food reward and the control of intake. Adv Nutr. 2015;6:474-86. 
8. Hill JO, Peters JC. Environmental contributions to the obesity epidemic. Science. 1998;280:1371-4.

9. Weingarten HP. Conditioned cues elicit feeding in sated rats: a role for learning in meal initiation. Science. 1983;220:431-3.

10. Petrovich GD. Forebrain circuits and control of feeding by learned cues. Neurobiol Learn Mem. 2011;95:152-8.

11. Walker AK, Ibia IE, Zigman JM. Physiology \& behavior disruption of cue-potentiated feeding in mice with blocked ghrelin signaling. Physiol Behav. 2012;108:34-43.

12. Maren S. Neurobiology of Pavlovian fear conditioning. Annu Rev Neurosci. 2001;24:897-931.

13. Everitt BJ, Cardinal RN, Parkinson JA, Robbins TW. Appetitive behavior. Ann N Y Acad Sci. 2003;985:233-50.

14. Pavlov IP. The scientific investigation of the psychical faculties or processes in the higher animals. Science. 1906;24:613-9.

15. Stern SA, Kohtz AS, Pollonini G, Alberini CM. Enhancement of memories by systemic administration of insulin-like growth factor II. Neuropsychopharmacology. 2014;39:2179-90.

16. Phillips RG, LeDoux JE. Differential contribution of amygdala and hippocampus to cued and contextual fear conditioning. Behav Neurosci. 1992;106:274-85.

17. Petrovich GD, Ross CA, Gallagher M, Holland PC. Learned contextual cue potentiates eating in rats. Physiol Behav. 2007;90:362-7.

18. Carew TJ, Pinsker HM, Kandel ER. Long-term habituation of a defensive withdrawal reflex in aplysia. Science. 1972;175:451-4.

19. Sagar SM, Sharp FR, Curran T. Expression of c-fos protein in brain: metabolic mapping at the cellular level. Science. 1988;240:1328-31.

20. Stuber GD, Wise RA. Lateral hypothalamic circuits for feeding and reward. Nat Neurosci. 2016;19:198-205.

21. Frank S, Kullmann S, Veit R. Food related processes in the insular cortex. Front Hum Neurosci. 2013;7:499.

22. Sweeney P, Yang Y. An excitatory ventral hippocampus to lateral septum circuit that suppresses feeding. Nat Commun. 2015;6:10188.

23. Scopinho AA, Resstel LBM, Corrêa FMA. alpha(1)-Adrenoceptors in the lateral septal area modulate food intake behaviour in rats. Br J Pharmacol. 2008;155:752-6.

24. Ono T, Nishino H, Sasaki K, Fukuda M, Muramoto K-I. Role of the lateral hypothalamus and the amygdala in feeding behavior. Brain Res Bull. 1980;5:143-9.

25. Zhang Q, Li H, Guo F. Amygdala, an important regulator for food intake. Front Biol. 2011;6:82-5.

26. Cai H, Haubensak W, Anthony TE, Anderson DJ. Central amygdala PKC- $\delta(+)$ neurons mediate the influence of multiple anorexigenic signals. Nat Neurosci. 2014;17:1240-8.

27. Douglass AM, Kucukdereli H, Ponserre M, Markovic M, Gründemann J, Strobel C, et al. Central amygdala circuits modulate food consumption through a positive-valence mechanism. Nat Neurosci. 2017;20:1384-94.

28. Sweeney P, Yang Y. An inhibitory septum to lateral hypothalamus circuit that suppresses feeding. J Neurosci. 2016;36:11185-95.

29. Pérez CA, Stanley SA, Wysocki RW, Havranova J, AhrensNicklas R, Onyimba F, et al. Molecular annotation of integrative feeding neural circuits. Cell Metab. 2011;13:222-32.

30. Morton GJ, Cummings DE, Baskin DG, Barsh GS, Schwartz MW. Central nervous system control of food intake and body weight. Nature. 2006;443:289-95.

31. Gao Q, Horvath TL. Neurobiology of feeding and energy expenditure. Annu Rev Neurosci. 2007;30:367-98.

32. Jansen A, Havermans RC, Nederkoorn C. Cued overeating. In: Preedy VR, Watson RR, Martin CR, (eds). Handbook of behavior, food and nutrition. New York, NY: Springer; 2011. pp 1431-43.

33. Wardle J. Conditioning processes and cue exposure in the modification of excessive eating. Addict Behav. 1990;15:387-93.

34. Wang C-Y, Liao JK. A mouse model of diet-induced obesity and insulin resistance. Methods Mol Biol. 2012;821:421-33.

35. Yager LM, Robinson TE. Cue-induced reinstatement of food seeking in rats that differ in their propensity to attribute incentive salience to food cues. Behav Brain Res. 2010;214:30-34.

36. Morris MJ, Beilharz JE, Maniam J, Reichelt AC, Westbrook RF. Why is obesity such a problem in the 21 st century? The intersection of palatable food, cues and reward pathways, stress, and cognition. Neurosci Biobehav Rev. 2015;58:36-45.

37. Commins S, Cunningham L, Harvey D, Walsh D. Massed but not spaced training impairs spatial memory. Behav Brain Res. 2003;139:215-23.

38. Kogan JH, Frankland PW, Blendy JA, Coblentz J, Marowitz Z, Schütz G, et al. Spaced training induces normal long-term memory in CREB mutant mice. Curr Biol. 1997;7:1-11.

39. Wingard JC, Goodman J, Leong K-C, Packard MG. Differential effects of massed and spaced training on place and response learning: A memory systems perspective. Behav Process. 2015;118:85-89.

40. Berridge KC. Motivation concepts in behavioral neuroscience. Physiol Behav. 2004;81:179-209.

41. Sternson SM, Nicholas Betley J, Cao ZFH. Neural circuits and motivational processes for hunger. Curr Opin Neurobiol. 2013;23:353-60

42. Betley JN, Xu S, Cao ZFH, Gong R, Magnus CJ, Yu Y, et al. Neurons for hunger and thirst transmit a negative-valence teaching signal. Nature. 2015;521:180-5.

43. Livneh Y, Ramesh RN, Burgess CR, Levandowski KM, Madara JC, Fenselau H, et al. Homeostatic circuits selectively gate food cue responses in insular cortex. Nature. 2017;546:611-6.

44. Cole S, Hobin MP, Petrovich GD. Appetitive associative learning recruits a distinct network with cortical, striatal, and hypothalamic regions. Neuroscience. 2015;286:187-202.

45. Knight Za, Tan K, Birsoy K, Schmidt S, Garrison JL, Wysocki $\mathrm{RW}$, et al. Molecular profiling of activated neurons by phosphorylated ribosome capture. Cell. 2012;151:1126-37.

46. Ekstrand MI, Nectow AR, Knight ZA, Latcha KN, Pomeranz LE, Friedman JM. Molecular profiling of neurons based on connectivity. Cell. 2014;157:1230-42..

47. Reynolds SM, Zahm DS. Specificity in the projections of prefrontal and insular cortex to ventral striatopallidum and the extended amygdala. J Neurosci. 2005;25:11757-67.

48. Saper CB. Convergence of autonomic and limbic connections in the insular cortex of the rat. J Comp Neurol. 1982;210:163-73.

49. Yasui Y, Breder CD, Saper CB, Cechetto DF. Autonomic responses and efferent pathways from the insular cortex in the rat. J Comp Neurol. 1991;303:355-74.

50. Allen GV, Saper CB, Hurley KM, Cechetto DF. Organization of visceral and limbic connections in the insular cortex of the rat. $\mathrm{J}$ Comp Neurol. 1991;311:1-16.

51. Kusumoto-yoshida I, Liu H, Chen BT, Fontanini A, Bonci A. Central role for the insular cortex in mediating conditioned responses to anticipatory cues. Proc Natl Acad Sci USA. 2014;112:1190-5. https://doi.org/10.1073/pnas.1416573112.

52. Baldo BA, Spencer RC, Sadeghian K, Mena JD. GABA-mediated inactivation of medial prefrontal and agranular insular cortex in the rat: contrasting effects on hunger- and palatability-driven feeding. Neuropsychopharmacology. 2016;41:960-70. 